\title{
EXPERIÊNCIAS DE APRENDIZAGEM DE PORTUGUÊS LÍNGUA ADICIONAL NO CONTEXTO UNIVERSITÁRIO
}

Experiences of Learning Portuguese as an Additional Language in a University Context

\author{
Hiago Higor de LIMA, UFSJ ${ }^{1}$ \\ Carolina Vianini Amaral LIMA, UFSJ ${ }^{2}$
}

RESUMO: Este trabalho apresenta um estudo narrativo sobre experiências de aprendizagem de português como língua adicional (PLA) de sete estudantes de diferentes nacionalidades em caráter de imersão em contexto universitário no Brasil. A experiência é tomada como construto e unidade de análise (MICCOLI, 1997-2014) e os dados foram analisados com base no Marco de Referência de Experiências de Aprendizagem (MICCOLI, 2007b, 2010). Os resultados apontam similaridades entre as experiências de estudantes de PLA e as experiências de estudantes de inglês, documentadas por Miccoli (1997; 2007b, 2010). O contexto de imersão acadêmico-universitário, entretanto, é o diferencial nas experiências de aprendizagem de PLA, por trazer à tona questões relativas à interação entre culturas e ao acolhimento do estudante estrangeiro, que se relacionam, entre outros elementos, ao processo de internacionalização das universidades.

PALAVRAS-CHAVE: Experiências; Português como língua adicional; Internacionalização.

ABSTRACT: This paper presents a narrative study about learning experiences of seven different nationalities students of Portuguese as an additional language (PAL) in the context of immersion in Brazil. Experience, as a construct and unit of analysis (MICCOLI, 1997-2014), orientates data analysis, as well as the Framework of Learning Experiences (MICCOLI, 2007b, 2010). Results demonstrate similarities between experiences of learning PAL and experiences of learning English, documented by Miccoli (1997, 2007b, 2010). The academic immersion context, however, is the differential in PAL learning experiences, raising questions about interaction between cultures and welcoming the foreign student, which are related, among other elements, to the process of internationalization of universities.

KEY WORDS: Experiences; Portuguese as an additional language; Internationalization.

\footnotetext{
${ }^{1}$ Graduando do curso de Letras da UFJS. hiagohigor7@ gmail.com

${ }^{2}$ Docente do Departamento de Letras, Artes e Cultura da UFSJ e doutora em Linguística Aplicada (UFMG). carolvianini@ufsj.edu.br
} 


\section{INTRODUÇÃO}

No Brasil, há espaços a serem ocupados no que diz respeito à pesquisa sobre ensino e aprendizagem de português para falantes de outras línguas, especialmente em contextos específicos, tendo em vista a relativa incipiência da área (SAMPAIO, 2011). É preciso sempre lembrar que o ensino de língua portuguesa para estrangeiros requer conhecimentos teóricos e metodológicos diferentes daqueles necessários para o ensino-aprendizagem de língua materna, exigindo estudo e pesquisa.

A experiência, enquanto construto e unidade de análise (MICCOLI, 2007a, 2010, 2014), tem sido meio de documentar e compreender os processos de ensino-aprendizagem de línguas, com base no olhar daqueles que os vivenciam, mostrando-se profícua à medida que fomenta estudos aplicados a diferentes aspectos no âmbito do ensino, aprendizagem e formação de professores ${ }^{3}$.

A investigação de experiências de aprendizagem de línguas estrangeiras no contexto acadêmico-universitário se faz especialmente interessante frente aos movimentos decorrentes do fenômeno da globalização e crescente importância das políticas linguísticas, materializados, dentre outras formas, através do processo de internacionalização das instituições de ensino superior - situação relativamente nova para algumas instituições que fazem parte da realidade de ensino superior latino-americano (STALLIVIERI, 2002).

Este trabalho apresenta uma análise das experiências de aprendizagem de português de sete estudantes estrangeiros, no contexto universitário, buscando compreendê-las, a fim de ampliar o conhecimento sobre o processo de aprendizagem de línguas adicionais, além de propor ações para aprimorar o ensino de português como língua adicional (doravante PLA) nas universidades. Os resultados evidenciam que, assim como acontece com a aprendizagem de inglês por estudantes brasileiros (MICCOLI,1997; 2007b; 2010), as relações entre colegas, as ações do professor e as crenças de ensino-aprendizagem interferem na aprendizagem do português, bem como fatores externos à sala de aula. O contexto de imersão acadêmico-

\footnotetext{
${ }^{3}$ Para compilação de pesquisas com foco na experiência vide MICCOLI, L. (org.). Pesquisa Experiencial em Contextos de Aprendizagem: uma Abordagem em Evolução. Campinas, SP: Pontes Editores, 2014.
} 
universitário, entretanto, é o diferencial nessas experiências, por trazer à tona questões relativas à interação entre culturas e ao acolhimento do estudante estrangeiro, que podem ser relacionadas, entre outros elementos, ao processo de internacionalização das universidades.

\section{ENSINO E APRENDIZAGEM DE PLA NO CONTEXTO BRASILEIRO}

Em meados da década de 90, surgiram iniciativas de ensino para a formação de professores em Português Língua Estrangeira (PLE) por meio de trabalhos acadêmicos e projetos de pesquisa sobre o tema. Multiplicaram-se, também, as publicações e eventos científicos focalizados nessa temática, sendo criada, em 1992, a SIPLE - Sociedade Internacional de Português Língua Estrangeira, ampliando a inserção do PLE na comunidade acadêmica e na sociedade em geral.

As pesquisas na área de português como língua não materna têm recebido diferentes nomes, dentre eles os mais comuns são PLE - Português língua estrangeira e PLA- Português língua adicional. Embora nesse trabalho a nomenclatura escolhida tenha sido PLA, a ideia aqui não é escolher um termo em detrimento de outrem. Conforme Judd et al (2003, p.85), usa-se o termo 'adicional' por este se aplicar a todas, exceto a primeira língua do estudante e por referir-se aos alunos que não compartilham do mesmo sistema simbólico, no caso o português brasileiro. Ao escolher o termo adicional, objetiva-se destacar a natureza intercultural das sociedades contemporâneas, exaltando a "coexistência de várias línguas (...)" (JORDÃO, 2014, p. 31).

O Português como língua adicional figura nos estudos da Linguística Aplicada como uma área bastante jovem (SAMPAIO, 2011), porém muito vigorosa. Gondim; Mendes (2011) destacam a área de PLA como importante campo de investigação na atualidade e elencam uma série de trabalhos, com variados focos, desenvolvidos no Brasil na última década. Tosatti (2009), por sua vez, apresenta uma série de pesquisas recentes que têm como foco o livro didático de PLA. Sampaio (2011) traça um panorama dos estudos em PLA no Brasil, documentando seu crescimento e apresentando um levantamento bibliográfico dos temas mais recorrentes nas pesquisas nessa área. Ele ressalta que embora se tenha uma produção científica bastante extensa disponível atualmente, ainda são poucos os trabalhos que têm o aluno como foco de estudo. 
Ademais, os novos fluxos migratórios no Brasil têm fomentado ações de ensino e pesquisa, contribuindo para a consolidação da área de Português como Língua de Acolhimento. O trabalho de Lopez (2016), por exemplo, oferece uma revisão cuidadosa sobre o tema e propõe princípios para o planejamento de cursos de Português como Língua de Acolhimento.

\section{O PROCESSO DE INTERNACIONALIZAÇÃO DAS UNIVERSIDADES}

A internacionalização tem como objetivo prioritário, para os órgãos governamentais, colocar o Brasil em níveis de destaque nos rankings internacionais científicos e acadêmicos (ZOPPI FONTANA, 2009). Senhoras (2006), no entanto, explicita a relação das universidades com a internacionalização, cujo papel a seu ver, deve abranger mais que o interesse de alguns cientistas e pesquisadores, transformando-se em uma lógica coletiva institucionalizada, dado o amadurecimento da universidade às relações transnacionais.

Segundo Stallivieri (2002), a internacionalização das instituições de ensino tem sido o gatilho para a melhoria da qualidade do ensino e da pesquisa, uma vez que proporciona condições para o desenvolvimento dos países e o incremento da qualidade de vida das pessoas. A cooperação internacional passa a ser um objetivo comum das sociedades científicas mundiais, pois, através da internacionalização das instituições, assegura-se a qualidade e a eficácia na renovação e na socialização do conhecimento produzido.

Assim, como afirma Bizon (2013),

como a internacionalização das universidades está intrinsicamente relacionada às políticas estabelecidas para o seu funcionamento, inclusive às políticas de línguas, é preciso que elas estejam claramente formuladas, fazendo parte de um projeto articulado em todas as instâncias da instituição. Nesse sentido, não é possível que a internacionalização se efetive de maneira sustentável sem que as instituições incluam no documento de sua Missão o que entendem, afinal, por internacionalização, e sem que, no cerne dessa conceituação, esteja a noção de processo, e não apenas de atividade. (p.47)

Para Knight (2008, p.08), aprender uma língua é uma introdução ao aprendizado de outra cultura e outra perspectiva ou percepção de mundo que, combinada com habilidades elevadas de comunicação intercultural são importantes atributos para graduandos de faculdades e universidades. 
Knight (2004), ao discutir os vários recortes do movimento de internacionalização, defende, a partir de Wachter (2003), que é no nível institucional que o verdadeiro processo de internacionalização está ocorrendo, fenômeno conhecido como 'internacionalização em $\operatorname{casa}^{4}$ :

O termo internacionalização em casa foi desenvolvido para chamar a atenção para aqueles aspectos da internacionalização que acontecem no âmbito do campus universitário, ou seja, a dimensão intercultural e internacional no processo de ensinoaprendizagem, as atividades extracurriculares, e as relações com grupos locais étnicos e culturais (Wachter, 2003, p. 6). (KNIGHT, 2004, p. 17, grifos da autora).

Esse cenário convida as universidades a "repensarem seu papel diante da sociedade, como instituições que abrigam a multiplicidade de valores e opiniões e que enfatizam o caráter universal do conhecimento" (STALLIVIERI, 2002, p. 01). Por isso, a urgência de universidades desenvolverem planos bem estruturados de política linguística que, dentre outros elementos, promovam a valorização da diversidade linguística e cultural, bem como a democratização do acesso ao ensino de idiomas.

$\mathrm{O}$ processo de internacionalização em casa, quando reflexivo e estruturado conscientemente, configura-se como uma maneira alternativa de alavancar o processo de internacionalização das universidades, trazendo benefícios tanto para a universidade anfitriã quanto para os alunos estrangeiros que nela decidem estudar. Assim, o preparo de técnicos, discentes e docentes na acolhida desses alunos torna-se primacial, proporcionando-lhes maiores possibilidades de adaptação ao ambiente e, principalmente, oportunidades de aprofundar o conhecimento sobre o contexto universitário local, a língua e a cultura do país, um dos motivos pelos quais o aluno almeja o intercâmbio. Por outro lado, a comunidade acadêmica da universidade anfitriã tem, também, a oportunidade de prática de outro idioma, em um processo de interação intercultural que contribui para a diminuição das fronteiras culturais.

\footnotetext{
${ }^{4}$ Tradução dos autores.
} 


\section{PESQUISA EXPERIENCIAL}

Há anos a experiência de estudantes e professores de línguas tem sido objeto de pesquisa de Miccoli (1997; 2007a; 2007b; 2010; 2014), documentando e compreendendo os processos de ensino-aprendizagem de língua estrangeira em salas de aula com base no olhar daqueles que os vivenciam. Miccoli (2007a) defende um novo tratamento da experiência na Linguística Aplicada, constituindo-a como construto e unidade de análise.

Miccoli (2010) define a experiência como

processo de natureza complexa e orgânica que constela em si várias outras vivências relacionadas, formando uma teia de relações dinâmicas entre aqueles que a vivenciam, no meio da qual se dá a experiência. Isso faz da experiência ponto de partida para a reflexão, com implicações para sua compreensão, para transformação de seu sentido original, bem como de quem a vivencia (p.31-32).

Partindo de uma percepção de aprendizagem como um processo socialmente situado e de relatos das vivências de estudantes, Miccoli (2010, p.38-39) delineia a natureza de aprendizagem de língua estrangeira em sala de aula como processo dual - parte pessoal (experiências individuais) e parte social (experiências coletivas), confirmando a sala de aula como espaço de diversidade cultural.

As experiências individuais se remetem à personalidade do aprendiz, suas motivações, metas e objetivos, história pessoal, cultural e ao próprio contexto de aprendizagem, podendo levar a experiências totalmente distintas na mesma sala de aula. Assim, essas experiências apontam a importância de entender os motivos que subjazem à aprendizagem em sala de aula. Ao identificar, via análise, motivos, objetivos e metas - ou sua ausência - para a aprendizagem, podem-se traçar cursos de ações visando potencializar resultados (MICCOLI, 2010, p. 56). As experiências coletivas, por sua vez, surgem da identificação de similaridades nas experiências de estudantes, revelando que "aprender língua estrangeira em sala de aula implica atividade complexa, em cuja realização emergem seu lado social e emocional, sua dimensão socializadora e coletiva" (MICCOLI, 2010, p. 59-60).

As experiências conglomeram diferentes dimensões da aprendizagem, sendo de natureza cognitiva, social, afetiva, contextual, pessoal, conceptual e futura. Cada uma dessas categorias é composta de subcategorias que descrevem diferentes elementos envolvidos no processo de aprendizagem, organizadas em um Marco de Referência para Categorização de 
Experiências de Estudantes (vide ANEXO I), que não é um instrumento estático. Ao contrário, ele se adapta aos elementos que emergem no processo investigado, possibilitando a identificação de especificidades das experiências destacadas nas narrativas e que intervêm nos processos vivenciados pelos participantes. Tendo a experiência como unidade de análise, o marco é concebido como um ponto de partida que media a análise das narrativas, possibilitando análises detalhadas e contextualizadas (MICCOLI, 2014).

O Marco de Referência já foi adaptado a diferentes contextos de pesquisa ${ }^{5}$, mas não, ainda, à aprendizagem de português brasileiro por falantes de outras línguas. Experiências de aprendizagem de inglês de estudantes universitários brasileiros foram subsídio para o início do processo de categorização de experiências (MICCOLI, 1997). Desta forma, o processo inverso pode revelar aspectos interessantes ainda não capturados. Muitos são os elementos que podem emergir da investigação da experiência, especialmente quando se considera que o ensinoaprendizagem de uma nova língua requer muito além do conhecimento relativo ao seu sistema, envolvendo visões sócio-histórico-culturais. Nesse ponto, a investigação de experiências de aprendizagem de PLA pode explicitar inter-relações entre aspectos caros à Linguística Aplicada e à área de ensino-aprendizagem de línguas, como questões relativas à interculturalidade no ensino de PLA, às identidades cultural e idiomática, à internacionalização do ensino superior, às políticas para o ensino de português para estrangeiros, entre outras.

\section{METODOLOGIA}

Para alcançar os objetivos propostos, apoiamo-nos nos pressupostos da pesquisa narrativa (CLANDININ E CONNELLY, 2000; LIEBLICH; TUVAL-MASHIACH; ZILBER, 1998). Em consonância com os pressupostos da pesquisa qualitativo-interpretativa foram utilizados três instrumentos de coleta de dados, quais sejam: 1) um questionário com itens abertos, possibilitando aos alunos escreverem narrativas que buscassem explorar suas

\footnotetext{
${ }^{5}$ Para descrições de adaptações do marco de referência a diferentes contextos, ver MICCOLI (2014).
} 
percepções pessoais, crenças e opiniões (vide anexo II); 2) observação das aulas; 3) notas de campo, que possibilitaram uma visão mais detalhada e pessoal dos relatos.

As narrativas foram escritas em horário extraclasse e puderam ser entregues de forma impressa ou via e-mail. Conversas informais contribuíram para o entendimento de pontos ainda obscuros na escrita dos participantes. As observações das aulas e as notas de campo contribuíram para reforçar alguns pontos destacados nas narrativas, além de lançar luz sobre pontos não apresentados nas mesmas.

A fim de obter dados mais robustos para análise, a pesquisa foi realizada em duas turmas, sendo uma de nível intermediário, constituinte do curso de Português ofertado pela Assessoria Internacional da instituição, que atende alunos estrangeiros cursando graduação ou pós-graduação, e a outra de nível elementar, parte de um projeto de extensão do Departamento de Letras, Artes e Cultura, que atende não só alunos estrangeiros vinculados à universidade, mas também à comunidade externa. Sete alunos aceitaram participar da pesquisa: quatro do curso do projeto de extensão e três do curso da Assessoria que, respectivamente, têm seu perfil traçado no quadro a seguir. Contudo, para preservar a identidade dos participantes, estes tiveram seus nomes reais substituídos por nomes fictícios escolhidos por eles:

\begin{tabular}{|c|c|c|c|c|}
\hline $\begin{array}{l}\text { Nome } \\
\text { fictício }\end{array}$ & $\begin{array}{l}\text { Nacionalidade } \\
\text { e idade }\end{array}$ & $\begin{array}{l}\text { Há quanto tempo já } \\
\text { está no Brasil e contato } \\
\text { anterior com a língua } \\
\text { portuguesa }\end{array}$ & $\begin{array}{l}\text { Propósito de } \\
\text { estadia no Brasil }\end{array}$ & $\begin{array}{l}\text { Contato com outras } \\
\text { línguas adicionais ou } \\
\text { vivência em outros países }\end{array}$ \\
\hline Armando & $\begin{array}{l}\text { Australiano, } \\
24\end{array}$ & $\begin{array}{c}09 \text { meses. Começou a ter } \\
\text { contato com a língua } \\
\text { portuguesa desde } 2014, \\
\text { mesmo ano que viajou } \\
\text { para o Brasil. }\end{array}$ & $\begin{array}{l}\text { Motivos } \\
\text { pessoais, com o } \\
\text { objetivo de } \\
\text { comunicar-se } \\
\text { melhor com as } \\
\text { pessoas. }\end{array}$ & $\begin{array}{l}\text { Não tinha contato com } \\
\text { outras línguas adicionais } \\
\text { nem havia morado em } \\
\text { outro país. }\end{array}$ \\
\hline Bryan & $\begin{array}{c}\text { Estadunidense } \\
, 23\end{array}$ & $\begin{array}{l}03 \text { meses. Teve aula } \\
\text { particular de português } \\
\text { por } 05 \text { meses antes de } \\
\text { sua vinda para o Brasil. }\end{array}$ & $\begin{array}{c}\text { Bolsista do } \\
\text { Programa } \\
\text { Fulbright } \\
\text { (English } \\
\text { Teaching } \\
\text { Assistant) na } \\
\text { Instituição. Tinha } \\
\text { interesse na } \\
\text { cultura brasileira. }\end{array}$ & $\begin{array}{c}\text { Estudou latim por } 06 \text { anos } \\
\text { e espanhol por } 02 \text { anos. } \\
\text { Ainda não havia morado } \\
\text { em outro país. }\end{array}$ \\
\hline
\end{tabular}


REVISTA X, Curitiba, volume 12, n.2,p.65-88,2017

\begin{tabular}{|c|c|c|c|c|}
\hline Caio & Francês, 34 & $\begin{array}{c}06 \text { meses. Já havia vindo } \\
\text { ao Brasil duas vezes: em } \\
2012 \text {, por } 2 \text { meses e } \\
2015 \text {, por } 4 \text { meses. } \\
\text { Embora não tivesse } \\
\text { estudado formalmente, } \\
\text { teve muito contato com } \\
\text { nativos brasileiros, desde } \\
2010 .\end{array}$ & $\begin{array}{c}\text { Caio trabalhava } \\
\text { em uma pousada. } \\
\text { Como pretendia } \\
\text { morar no Brasil, } \\
\text { o aluno queria } \\
\text { alcançar fluência } \\
\text { e acurácia na } \\
\text { língua } \\
\text { portuguesa. }\end{array}$ & $\begin{array}{c}\text { Já havia estudado inglês } \\
\text { informalmente e morado } \\
\text { nos Estados Unidos por um } \\
\text { ano. }\end{array}$ \\
\hline Dafne & $\begin{array}{l}\text { Estadunidense } \\
\qquad, 23\end{array}$ & $\begin{array}{l}\text { O6 meses. Já estudava } \\
\text { informalmente por } 02 \\
\text { anos com recursos da } \\
\text { internet. }\end{array}$ & $\begin{array}{c}\text { Bolsista do } \\
\text { Programa } \\
\text { Fulbright } \\
\text { (English } \\
\text { Teaching } \\
\text { Assistant) na } \\
\text { Instituição. } \\
\text { Gostava muito de } \\
\text { línguas e } \\
\text { manifestou } \\
\text { interesse pela } \\
\text { cultura brasileira. }\end{array}$ & $\begin{array}{l}\text { Já havia feito um semestre } \\
\text { de intercâmbio na Espanha. }\end{array}$ \\
\hline Estevão & $\begin{array}{l}\text { Colombiano, } \\
28\end{array}$ & $\begin{array}{c}14 \text { meses. Não tinha } \\
\text { contato com o português } \\
\text { antes, nem conhecia o } \\
\text { Brasil. }\end{array}$ & $\begin{array}{c}\text { Bolsista de } \\
\text { mestrado em } \\
\text { Letras. Não } \\
\text { demonstrava } \\
\text { interesse pela } \\
\text { língua } \\
\text { portuguesa. }\end{array}$ & $\begin{array}{l}\text { Não tinha contato com } \\
\text { outras línguas e nem } \\
\text { viajado a outros países. }\end{array}$ \\
\hline Fábio & $\begin{array}{l}\text { Colombiano, } \\
39\end{array}$ & $\begin{array}{l}14 \text { meses. Começou a } \\
\text { estudar português desde } \\
\text { 2014, porém não foi um } \\
\text { estudo contínuo. Ainda } \\
\text { não havia vindo ao } \\
\text { Brasil. }\end{array}$ & $\begin{array}{c}\text { Bolsista de } \\
\text { mestrado em } \\
\text { Educação. Queria } \\
\text { conhecer mais } \\
\text { sobre o Brasil e } \\
\text { sobre o povo } \\
\text { brasileiro. }\end{array}$ & $\begin{array}{c}\text { Já havia morado no México } \\
\text { por } 02 \text { anos. }\end{array}$ \\
\hline Gabriel & $\begin{array}{l}\text { Equatoriano, } \\
38\end{array}$ & $\begin{array}{c}14 \text { meses. Estudou } \\
\text { português por apenas } \\
\text { dois meses, antes de sua } \\
\text { chegada ao Brasil pela } \\
\text { primeira vez. }\end{array}$ & $\begin{array}{c}\text { Bolsista de } \\
\text { mestrado em } \\
\text { Engenharia. } \\
\text { Pretendia dar } \\
\text { sequência aos } \\
\text { seus estudos no } \\
\text { Brasil - } \\
\text { doutorado - ou } \\
\text { retornar para o } \\
\text { Equador e dar } \\
\text { aulas de } \\
\text { português. }\end{array}$ & $\begin{array}{l}\text { Não tinha experiências } \\
\text { com outras línguas ,nem } \\
\text { morado em outros países. }\end{array}$ \\
\hline
\end{tabular}


A análise dos dados seguiu as seguintes etapas: a) leitura das narrativas; b) categorização de experiências dos estudantes conforme o 'Marco de Referência de Experiências de Aprendizagem’ (MICCOLI, 2007b; 2010); c) teste de validação da codificação, seguindo procedimentos de Miccoli (1997); d) cálculos percentuais de recorrência de cada tipo de experiência para cada participante e representação destas em um gráfico; e) análise qualitativa das experiências, tendo o gráfico como referência, buscando compreender a natureza das experiências dos estudantes no contexto acadêmico-universitário; f) análise das anotações de campo e g) triangulação dos resultados das análises das experiências, observações e anotações de campo.

\section{RESULTADO E DISCUSSÕES}

De forma a facilitar a visualização e apresentação dos resultados, será apresentado, primeiramente, um gráfico que expõe os resultados percentuais da ocorrência das experiências dos alunos. Em seguida, discutir-se-á a natureza dos relatos dos estudantes ${ }^{6}$, focalizando os elementos que se destacaram em suas narrativas, bem como suas relações com a aprendizagem, que permitem uma análise interpretativa dos resultados.

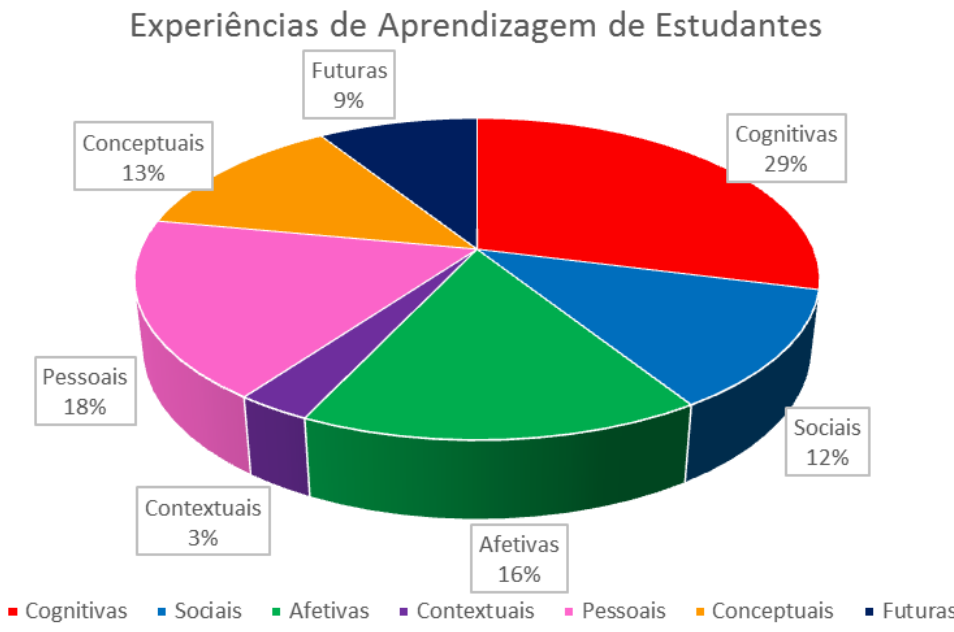

Gráfico 1: Levantamento da natureza das experiências nas narrativas dos estudantes de PLA

\footnotetext{
${ }^{6}$ Os relatos foram minimamente modificados, alterando-se apenas questões gramaticais que pudessem comprometer sua compreensão.
} 
É importante esclarecer que a representação da natureza das experiências não segue uma lógica 'quantidade-relevância'. As experiências estão imbricadas umas às outras, sendo separadas apenas a título de análise, dado que nem sempre maior quantidade implica maior relevância para o processo de aprendizagem.

\section{Experiências Cognitivas}

As experiências cognitivas referem-se ao processo de aprender, entender e adquirir conhecimentos por intermédio de atividades realizadas em sala de aula.

As experiências cognitivas predominam no relato dos estudantes, conforme ilustra o gráfico. Como já apontado por Miccoli (2014, p.51), "quando o aluno narra sua experiência em sala de aula, destaca sua preocupação com a aprendizagem". Nos relatos dos estudantes de PLA, sobressaem as referências a experiências relativas à identificação de objetivos, dificuldades e dúvidas, demonstrando que os alunos têm consciência e controle sobre seus processos de aprendizagem. Os relatos abaixo ilustram essa dimensão:

Armando: A parte mais difícil é a velocidade em que os nativos falam e palavras formais e informais (gírias) que geralmente não são muito ensinadas em texto.

Bryan: Especificamente, eu gosto de atividades que repassar a matéria algumas vezes e que nos preguntar a usar a língua em um jeito natural. Geralmente, eu acho que atividades gramaticas do livro são demasiadas fáceis e prefiro produzir minhas próprias ideias em português.

Caio: Acho que, durante a aula de português, para mim, são os jogos de língua e os exercícios que me fazem avançar. Também adoro conversar, mas agora não é minha maior dificuldade. Eu já tenho um vocabulário bom, mas eu sinto a falta de gramática e de conjugação. Minha principal dificuldade agora é a escrita. 


\section{Experiências Sociais}

Como o próprio nome sugere, referem-se ao domínio social, às maneiras como a interação se organiza e ao modo como os estudantes vivenciam a relação com seus pares: demais estudantes e professor.

Os resultados de Miccoli (1997; 2010) confirmam a sala de aula como espaço dividido em círculos de interação, ou seja, grupos estabelecidos por algum tipo de afinidade. Esses grupos determinam as relações interpessoais em sala, sejam elas de interação ou de tensão. Por meio de observações realizadas durante a pesquisa, pôde-se perceber que as relações interpessoais entre os alunos eram majoritariamente de interação. Mesmo havendo alunos de mesma nacionalidade, eles não formavam grupos étnicos na sala de aula, demonstrando, mais uma vez, um posicionamento consciente e autônomo. No entanto, há relatos que denotam tensão nas relações interpessoais, com implicações para a aprendizagem.

Fábio, por exemplo, descreve seu incômodo causado pela entrada de estudantes novatos na turma, ocasionando repetição do conteúdo, fato que fez com que ele se sentisse frustrado, impactando em seu processo de aprendizagem:

Fábio: De início, nas aulas havia três estrangeiros e estabelecemos um horário para as aulas uma vez por semana, com duração de $1 \mathrm{~h} 30 \mathrm{~min}$. No início foi muito bom, mas depois estudantes novatos haviam ingressado na aula, fazendo com que o professor ficasse repetindo as mesmas aulas o tempo todo. [...] $O$ que mais dificultou na sala de aula foi a atitude do professor, uma atitude de não considerar os diferentes ritmos de aprendizagem, diferentes pessoas com diferentes níveis de português. Além disso, é uma estratégia ruim repetir as aulas muitas vezes porque nós ficamos chateados por não ver o progresso, o aprimoramento.

O relato de Fábio evidencia como as decisões e ações docentes podem afetar a aprendizagem, de forma negativa ou positiva, conforme já documentado em outras pesquisas com foco na experiência (ARRUDA, 2014; MICCOLI, 1997; LIMA, 2009; 2014, entre outros), o que levanta questões relacionadas a formação docente. Professores precisam ser conscientes de suas potencialidades e possibilidades em relação a seus ambientes de ensino, compreendendo que sua prática pode promover ou inibir oportunidades de aprendizagem. 
No contexto acadêmico, tipicamente de imersão, as referências ao domínio social se expandem para além da sala de aula de português. Gabriel explica que não recebeu nenhum tipo de tratamento diferenciado, nem por parte dos professores, nem de colegas, por ser aluno estrangeiro, impelindo-o a buscar, por si só, estratégias para superar as dificuldades:

Gabriel: Os professores que tive, em sua maioria, falavam normalmente. Não tive nenhum tratamento especial por causa disso na sala. Em nenhum momento os professores mudaram de estratégia porque eu estava na sala. Mas não tive maiores problemas por causa disso, porque na área da engenharia os termos utilizados eram muito técnicos, então eu entendia quase sempre, mas se houvesse alguma brincadeira ou piada eu não entendia nada. Ao longo do percurso eu fui me adaptando.

No que tange aos processos de internacionalização das universidades e de mobilidade acadêmica, fatores como obstáculos na comunicação entre professores e alunos, diferenças culturais e de sistemas educacionais são dificuldades típicas que podem, entretanto, ser antecipadas. Professores e discentes precisam estar preparados para lidar com o 'estrangeiro', compreendendo que a participação de toda a comunidade universitária pode promover o acolhimento e facilitar a aprendizagem desse estudante. Mais ainda, é preciso compreender que essa interação pode ser proveitosa para todos os envolvidos.

Gabriel retoma a questão da interação com estudantes estrangeiros no ambiente de mestrado:

Gabriel: Já nas aulas [do mestrado] com os meus colegas foi um pouco difícil, porque eles não me corrigiam quando eu falava algo de errado. Eles não me corrigiam por respeito ou medo de que eu me sentisse mal, mas se eu perguntasse a pronúncia de determinada palavra eles me respondiam.

Acima de tudo, a experiência de Gabriel traz à tona a necessidade de processos de internacionalização integralizadores, que envolvam toda a comunidade acadêmica. A esse respeito, Stallivieri (1998) defende que a definição de estratégias e de ações que fortaleçam a integração cultural entre diferentes comunidades devem ser discutidas pelos conselhos superiores a fim de que se estabeleçam ações a longo prazo e se desenvolvam posturas proativas para o mútuo reconhecimento das diversidades culturais. 


\section{Experiências afetivas}

Neste domínio, encontram-se as experiências relacionadas aos elementos afetivos, revelando como emoções e sentimentos podem afetar a aprendizagem, de forma positiva ou negativa, conforme evidenciam os relatos:

Bryan: Eu gosto de aprender português. Agora consigo me comunicar e formar relações com pessoas porque estou morando no Brasil.

Estevão: Para mim tem sido uma oportunidade aprender uma língua tão diferente, mas também muito próxima ao espanhol. $O$ impacto do português na minha vida tem sido muito positivo porque tem sido o meio para eu conhecer uma cultura diferente.

Dafne: (...) verdadeiramente eu me apaixonei pela língua portuguesa e pela cultura brasileira como nunca pensei que eu iria.

Armando: Eu sempre tenho ciúmes dos outros alunos da classe que falam espanhol ou vêm de um país que fala língua espanhola; eles estão sempre aprendendo o português mais rápido do que eu.

Assim como nos resultados de Miccoli (1997; 2007b; 2010), as experiências de estudantes de PLA referentes aos sentimentos também se sobressaem em relação às demais subcategorias. Entretanto, em comparação com as experiências relativas à motivação, interesse e esforço, os relatos dos estudantes de PLA demonstram que eles se sentem, de um modo geral, mais motivados na aprendizagem de português. O caráter de imersão em que se encontram configura-se como fator determinante para tais sentimentos, como evidenciam os relatos de Bryan, Estevão e Dafne, principalmente. A proximidade desses alunos com a língua portuguesa e com a cultura brasileira serviu como mola propulsora para a aprendizagem de português, corroborando a proposição de que um certo grau de afiliação ${ }^{7}$ ao idioma (PAIVA, 2014, p. 61) auxilia no processo de aquisição de línguas adicionais, evidenciando a influência de elementos culturais e afetivos nesse processo.

\footnotetext{
${ }^{7}$ Paiva (2014, p. 61) propõe o uso do termo afiliação que, a seu ver, não carrega a ideia de perda da identidade, "no sentido de identificação com a língua e/ou com os participantes de uma comunidade de fala".
} 
Já o relato de Armando ancora-se na crença de que saber espanhol ajuda na aprendizagem do português por serem línguas próximas. Sobre questões interculturais que podem afetar a aprendizagem, Sampaio (2015) adverte que o professor, em um ambiente multicultural como no ensino de PLA em caráter de imersão, deve procurar meios de suavizar e relativizar as diferenças culturais e o modo como o membro imerso na nova cultura percebe a si mesmo e os potenciais interagentes em contato.

\section{Experiências contextuais}

As experiências que abarcam esse domínio incluem as referências ao meio em que a aprendizagem ocorre revelando como questões de nível micro (institucional) e de nível macro (status da língua estrangeira) podem afetar a aprendizagem.

Nas narrativas dos alunos de PLA houve pouca referência ao domínio contextual. A duração da pesquisa ${ }^{8}$ exigiu um processo mais enxuto de coleta de dados. Certamente, outras ferramentas, como entrevistas orais, gravação das aulas etc., poderiam gerar dados ainda mais robustos. Ainda assim, foi possível documentar referências, no âmbito institucional, pelo menos, que demonstram o comprometimento dos setores da universidade no atendimento a alunos em mobilidade acadêmica, bem como a preparação desses setores no que tange o processo de internacionalização, conforme o excerto abaixo ilustra:

Estevão: Como bolsista internacional, eu tive todo o apoio da Assessoria Internacional da Universidade, sendo que, foi oferecido até um curso de português para os estudantes estrangeiros.

É de suma importância que os vários setores da universidade estejam aptos a receber e acolher o aluno estrangeiro, proporcionando-lhes qualidade no atendimento prestado. Potencializar o preparo dos setores no atendimento desses alunos é, sem dúvida, uma dimensão essencial da internacionalização em casa. As universidades devem dispor de setores estruturados e organizados para a realização de projetos efetivos de cooperação internacional, contando com equipes de gestores competentes, qualificados e bem formados (STALLIVIERI, 2002).

\footnotetext{
${ }^{8}$ Essa foi uma pesquisa de Iniciação Científica, com duração de 1 ano.
} 


\section{Experiências pessoais}

Este domínio contém experiências relatadas sobre como a vida pessoal do estudante pode afetar sua aprendizagem, sendo de diversos tipos: relacionadas ao nível econômico, experiências anteriores de aprendizagem, experiências fora da sala de aula ou ainda relacionadas à conciliação (ou não) entre trabalho e estudo. Os relatos de Bryan e Dafne, respectivamente, ilustram algumas dessas experiências:

Bryan: Na verdade, eu comecei a aprender português em setembro de 2015 com aulas particulares na minha cidade nos Estados Unidos. Durante as aulas, minha professora e eu falávamos por duas horas em português.

Dafne: Também estou envolvida na comunidade católica aqui e participo em alguns grupos de oração e estudos da Bíblia. [...] Minha vida espiritual é uma forma ótima de melhorar o português porque é um ambiente confortável e seguro para mim é algo que me interessa muito.

As experiências anteriores, como as relatadas por Bryan, são relevantes porque influenciam diretamente o processo de aprendizagem por serem insumo para novas experiências, em um processo de retroalimentação. No caso de Bryan essas experiências foram bem-sucedidas, mas, não raro, experiências passadas de aprendizagem podem ser frustrantes ou negativas. Daí a importância de se refletir sobre essas vivências anteriores de modo que possam ser reconfiguradas.

O relato de Dafne, por sua vez, ilustra como vivências fora de sala de aula podem contribuir não só com a aprendizagem da língua, mas também com o processo de integração cultural e social. Para Dafne, os grupos de oração e estudo da Bíblia caracterizam-se como atividades que vão além de suas necessidades enquanto estudante de português para contemplar, também, interesses próprios que, por sua vez, a auxiliam a agir na comunidade local.

É interessante, portanto, levantar meios que possibilitem a oportunidade de eventos para estrangeiros, fazendo-os aprimorar o conhecimento não somente linguístico, mas também cultural e local do país no qual estão imersos. Atividades que ajudem os estudantes a desenvolver a compreensão do mundo e as competências interculturais promovem formação 
integralizadora e contribuem com o processo de internacionalização em casa, que, lembrando, não se limita ao ambiente acadêmico-universitário.

\section{Experiências conceptuais}

Este domínio contém referências a experiências que expressam concepções, conceitos e crenças, manifestadas na compreensão dos acontecimentos em sala de aula. As experiências conceptuais diferem das demais por não apenas representarem experiências vivenciadas 'realmente', podendo também, representar experiências indiretas (imaginadas, sentidas ou ainda aprendidas nas experiências dos outros). Os seguintes excertos ilustram essa dimensão:

Dafne: As aulas [de PLA] são um suplemento essencial para mim e eu vejo a diferença quando eu não tenho as aulas.

Dafne compreende o contexto formal de aprendizagem, no caso a sala de aula de PLA, como algo essencial à sua aprendizagem, mesmo estando em contato com a língua portuguesa o tempo todo devido à imersão.

Uma crença bastante comum na aprendizagem de línguas, especialmente na aprendizagem de inglês, é a de que só se aprende a língua efetivamente no país onde ela é falada (BARCELOS, 1995-2007; MICCOLI, 1997-2014, entre outros). Nos relatos dos estudantes de PLA, a relevância da imersão no processo de aprendizagem do português se destaca, trazendo à tona a referida crença:

Estevão: $O$ fato é que, se eu não viesse para o Brasil, eu não aprenderia português.

Fábio: Ficar imerso no país de língua nativa é a melhor experiência para a pessoa poder melhorar todas as habilidades linguísticas.

O relato de Estevão, principalmente, aponta para a contínua necessidade de oferecer a estudantes oportunidades de reflexão sobre suas crenças de aprendizagem. É fato que o processo de imersão oferece infinitas possibilidades à aprendizagem de uma língua adicional, mas não é garantia única para a aprendizagem. Há diversas maneiras de se aprender uma língua, especialmente em uma sociedade cada vez mais tecnologizada. 


\section{Experiências futuras}

Referem-se às experiências ainda não vivenciadas, mas projetadas como possíveis de serem realizadas. Podem se referir a aspectos cognitivos, sociais ou afetivos, mas revelam haver algo que ainda precisa ser trabalhado ou alcançado.

Comparando as narrativas dos alunos de PLA com as narrativas dos alunos de inglês das pesquisas de Miccoli (1997;2010), nota-se que há similaridades entre os relatos: a maioria deles tem intenção de continuar a estudar a língua; tem vontade de progredir, reconhecendo, portanto, a necessidade de um plano de ação; tem a necessidade de desenvolver fluência na língua e desejam atingir alguma meta, como por exemplo, se tornar professor (a) da língua estudada, conforme ilustram os relatos a seguir:

Armando: Meus planos são um dia ser fluente na língua portuguesa, embora eu sei que isso vai demorar pelo menos mais dois ou três anos de comprometimento. Depois de ter aprendido português, minha intenção é também aprender espanhol, pois esta é uma língua que eu sempre quis aprender, devido ao seu uso internacional.

Dafne: Eu quero procurar uma maneira para manter e melhorar o português quando eu voltar para meu país. Se for encontrar mais aulas, encontrar uma oportunidade para dar aula se eu chegar a uma fluência suficiente, ou usar num trabalho.

Ao comentar sobre ações futuras, os estudantes sentem-se motivados a dar continuidade aos estudos de português e até de outras línguas, como no caso de Armando. Em ambos os relatos, percebe-se a consciência dos estudantes em relação ao seu processo de aprendizagem, evidenciando como a atribuição de metas e objetivos contribuem para o desenvolvimento da autonomia do estudante.

\section{CONSIDERAÇÕES FINAIS}

Nesta pesquisa buscou-se compreender as experiências que emergem do processo de aprendizagem de estudantes de PLA no contexto universitário. Refletir sobre as experiências de aprendizagem de português na sala de aula permite aos estudantes perceber e interagir com as próprias experiências internalizadas, abrindo possibilidade para ressignificação dessas 
experiências. Ao refletir sobre sua aprendizagem, falar sobre como aprendem uma língua, os estudantes tomam consciência e interpretam seus conhecimentos, sentimentos e concepções sobre os eventos em sala de aula, desenvolvendo sua autonomia enquanto aprendizes.

Por meio da análise dos dados, evidenciou-se que a sala de aula de PLA constitui-se como um "rico caldeirão intercultural" (LEROY E SOBRINHO, 2011) em que experiências das mais diversas afloram a todo instante, e, por constituírem-se como eventos de natureza complexa é interessante a continuidade de estudos, buscando explorar o tema com mais profundidade e capturar elementos que ultrapassam ao escopo desta pesquisa.

Acima de tudo, faz-se imprescindível repensar o papel e a importância de universidades no projeto de ensino de PLA. Destaca-se a necessidade de se recolher ideias e exemplos de boas práticas sobre o processo de internacionalização em casa que auxiliem a comunidade acadêmica a desenvolver competências interculturais e ampliar a compreensão do mundo. Para que isso ocorra, torna-se essencial que discentes, docentes e demais profissionais compreendam os benefícios da internacionalização das universidades e se evolvam no processo de acolhimento do estudante estrangeiro. Acolher, nesse sentido, toma proporções maiores do que apenas receber, significa proporcionar a valorização da diversidade linguística e cultural, promovendo, assim, a interação entre povos e culturas.

\section{REFERÊNCIAS}

BARCELOS, A. M. F. A cultura de aprender língua estrangeira (inglês) de alunos de Letras. 1995. Dissertação (Mestrado em Linguística Aplicada) - IEL, UNICAMP, Campinas, 1995.

Understanding teachers' and students' language learning beliefs in experience: A Deweyan Approach. 2000. Tese (Doutorado). The University of Alabama, Tuscaloosa, AL, USA, 2000.

. Reflexões acerca da mudança de crenças sobre ensino e aprendizagem de línguas. Revista Brasileira de Linguística Aplicada, Belo Horizonte, v. 7, n. 2, p. 109-138, 2007.

BIZON, A.C.C. Narrando o exame Celpe-Bras e o convênio PEC-G: a construção de territorialidades em tempos de internacionalização. Tese (Doutorado), Universidade Estadual de Campinas, Campinas, 2013.

CLANDININ. D.J. \& CONNELLY, F. M. Narrative Inquiry: Experience and Story in Qualitative Research. San Francisco: Jossey-Bass Publishers, 2000. 
GONDIM, A. A. L.; MENDES, KALINE ARAÚJO. O espaço dos gêneros orais em livros didáticos de PLE. In: VI SIGET - Simpósio Internacional de Estudos dos Gêneros Textuais, 2011, Natal. Simpósio Internacional de Estudos dos Gêneros Textuais: Gênero Textual/Discursivo e Letramento. Natal: UFRN ALAB, 2011. Disponível em: http://www.cchla.ufrn.br/visiget/pgs/pt/anais/Artigos/Ang\%C3\%A9lica\%20Lima\%20Gondim $\% 20$ (UFC) \%20e\%20Kaline\%20Ara\%C3\%BAjo\%20Mendes\%20(UFC).pdf. Acesso em: 07 Ag. 2017.

JORDÃO, C. M. ILA - ILF - ILE - ILG: Quem dá conta? Revista Brasileira de Linguística Aplicada: Belo Horizonte, v. 14, n. 1, 2014. pp. 13-40

JUDD, E. L.; TAN, L.; WALBERG, H. J. (Eds.) Teaching additional languages. UNESCO. International Academy of Education: International Bureau of Education, 2003.

KNIGHT, J. Internationalization Remodeled: Definition, Approaches, and Rationales. Journal of Studies in International Education, v. 8, n.1, Spring 2004, pp.5-32

KNIGHT, J. Higher Education in Turmoil: The changing of Internationalization. Sense Publishers: Canada, 2008.

LEROY, H.R.; SOBRINHO, J.C. Interculturalidade e ensino de português língua estrangeira. Anais do XV Congresso Nacional de Linguística e Filologia, Cadernos do CNLF, v. $15 \mathrm{n}^{\circ} 5$, t.2 Rio de Janeiro: CiFEFiL, 2011.

LIEBLICH, A., TUVAL-MASHIACH, R., \& ZILBER, T. Narrative research: reading, analysis, and interpretation. Newbury Park, CA: Sage, 1998.

LIMA, C. V. A. Experiências de indisciplina e aprendizagem: um estudo de caso em uma turma de um curso livre de inglês. 2009. 168f. Dissertação (Mestrado em Linguística Aplicada ao Ensino de Línguas Estrangeiras) - Faculdade de Letras, Universidade Federal de Minas Gerais, Belo Horizonte, 2009.

. Eu faço o que posso: experiências, agência e complexidade no ensino de língua inglesa. Tese (Doutorado) - Faculdade de Letras, Universidade Federal de Minas Gerais, Belo Horizonte, 2014.

LOPEZ, A. P. A. Subsídios para o planejamento de cursos de português como língua de acolhimento para imigrantes deslocados forçados no Brasil. Dissertação (Mestrado) Faculdade de Letras, Universidade Federal de Minas Gerais, Belo Horizonte, 2016.

MICCOLI, L. S. Learning English as a foreign language in Brazil: a joint investigation of learners' experiences in a university classroom. Unpublished PhD Dissertation. University of Toronto, Canada, 1997.

. Por um Novo Tratamento da Experiência na Linguística Aplicada ao Ensino de Línguas Estrangeiras. Revista Crop, n.12, p.263-283, 2007a. 
Experiências de estudantes em processo de aprendizagem de língua inglesa: por mais transparência. Revista de Estudos da Linguagem, v. 15, n. 1, p. 197-224, $2007 \mathrm{~b}$.

A Experiência na Linguística Aplicada ao Ensino de Línguas Estrangeiras: levantamento, conceituação, referências e implicações para pesquisa. Revista Brasileira de Linguística Aplicada, v.7, n.1, p. 208-248, 2007c.

Ensino e Aprendizagem de Inglês: Experiências, Desafios e Possibilidades. Campinas: Pontes Editores, 2010.

A evolução da pesquisa experiencial - uma trajetória colaborativa. In: MICCOLI, L. (org.) Pesquisa com foco na Experiência: uma teoria em evolução. Campinas, SP: Pontes Editores, 2014.

MICCOLI, L. S. e LIMA, C.V.A. Experiências em sala de aula: evidência empírica da complexidade no ensino e aprendizagem de LE. Revista Brasileira de Linguística Aplicada, v. 12, n. 1, p. 49-72, 2012.

PAIVA, V.L.M. O. Aquisição de Segunda Língua. São Paulo: Parábola Editorial, 2014.

SAMPAIO, G.H. Português como língua estrangeira: um estudo das relações entre experiências, crenças e motivações. Monografia apresentada ao Departamento de Letras da Universidade Federal de Viçosa. Viçosa, 2011.

. A negociação de categorias de pertencimento em interação intercultural na sala de aula de português como língua estrangeira. Dissertação (mestrado- Pós-graduação em Letras) Universidade Federal de Viçosa. Viçosa, MG, 2015.

SENHORAS, E. M. O Papel da Internacionalização das Universidades e a Projeção da Cooperação Internacional do MERCOSUL. In: III Seminário Internacional Ciência e Tecnologia na América Latina, 2006, Campinas. Anais do III Seminário Internacional Ciência e Tecnologia na América Latina. Campinas: Unicamp, 2006.

STALLIVIERI, L. O processo de Internacionalização nas Instituições de Ensino Superior. Revista do Conselho de Reitores das Universidades Brasileiras, v. 24, p. 35-57, 2002. Disponível em: < http://www.ucs.br/site/midia/arquivos/processo_internacionalizacao.pdf>. Acesso em 01/09/2017.

TOSSATTI, N. M. O aspecto funcional dos gêneros textuais em livros didáticos para ensino de português como segunda língua. Dissertação (Mestrado) - Faculdade de Letras, Universidade Federal de Minas Gerais, Belo Horizonte, 2009.

ZOPPI FONTANA, M. (Org.). O português do Brasil como língua transnacional. Campinas, SP: RG, 2009. 


\section{ANEXO I}

Experiências em Sala de Aula de Estudantes de Inglês (MICCOLI, 2007b, 2010, 2014)

\section{MARCO DE RERFERÊNCIA DE EXPERIÊNCIAS DE APRENDIZAGEM}

\section{Experiências Cognitivas referentes a}

Cog. 1. Atividades realizadas em sala de aula

Cog.2.Identificação de objetivos, Dificuldades e dúvidas

Cog. 3. Participação e de desempenho (referentes a prestar atenção, ler, discutir, refletir etc.)

Cog. 4. Experiências de aprendizagem (referentes ao que foi aprendido)

Cog. 5. Avaliação do ensino e/ou aprendizagem (avaliação das atividades propostas e da aprendizagem)

Cog. 6. Experiências paralelas às de sala de aula (referentes a deveres, materiais didáticos, avaliações e a outros eventos de aprendizagem)

Cog. 7. Estratégias de aprendizagem (prestar atenção, tomar nota, memorizar, fazer perguntas)

\section{Experiências Sociais referentes a}

Soc. 1. Interação e relações interpessoais (como estudantes interagem com colegas)

Soc. 2. Tensão nas relações interpessoais (competição, críticas, riscos)

Soc. 3. Ser estudante (como os estudantes se veem)

Soc. 4. Ser professor (relações de poder, interação professor-aluno, avaliação do

\section{Experiências Contextuais referentes a}

Ctx. 1. Instituição (matrícula, requerimentos, exigências do professor ou da instituição)

Ctx. 2. Meio extrainstitucional (governo, legislação, políticas da instituição)

Ctx. 3. Língua estrangeira (Status da LE)

Ctx. 4. Decorrência da pesquisa (atitudes e sentimentos)

Ctx. 5. Experiências do tempo (ou à falta de tempo)

\section{Experiências Pessoais referentes a}

Pes. 1. Nível socioeconômico (pessoal ou da escola onde estudam)

Pes. 2. Aprendizagen anteriores (de qualquer tipo)

Pes. 3. Vida pessoal (fora da sala ou na escola)

Pes. 4. Trabalho (como afeta os estudos, sobrecarga de trabalho)

\section{Experiências Conceptuais referentes} a

Cpt. 1. Ensino de LE (relação ideal professor-aluno, papel do professor etc.) 
professor)

Soc. 5. Grupos, dinâmicas (trabalhos ou dinâmicas de grupo)

Soc. 6. Turma (sala de aula e turma como unidade)

Soc. 7. Estratégias sociais (administração de competição, críticas, maus tratos e rivalidades)

\section{Experiências Afetivas referentes a}

Afe. 1. Experiências de sentimentos (positivos e negativos)

Afe. 2. Experiências de motivação, interesse e esforço

Afe. 3. Autoestima e atitudes (como se veem afetivamente)

Afe. 4. Atitudes do professor (atitudes e sentimentos do professor)

Afe. 5. Estratégias afetivas (administração de sentimentos)
Cpt. 2. Aprendizagem (geral, de línguas, papel do estudante etc.)

Cpt. 3. Aprendizagem pessoal (o próprio processo de aprendizagem)

Cpt. 4. O papel do estudante (responsabilidade, comportamentos típicos)

\section{Experiências Futuras referentes a}

Fut. 1. Intenções (planos ou ação para a próxima aula ou vez)

Fut. 2. Vontades (a algo difícil, importante para o processo)

Fut. 3. Necessidades (algo que é preciso mudar: fluência, comportamentos, sentimentos)

Fut. 4. Desejos (metas mais distantes, visões, sonhos) 


\section{ANEXO II}

\section{GUIA NARRATIVO}

Convido você, aluno (a), a redigir uma narrativa de seu processo de aprendizagem da língua portuguesa até o presente momento. Nesse relato, peço que você se sinta livre para comentar como tem sido sua trajetória no que concerne ao aprendizado da língua portuguesa, (suas experiências, crenças, dificuldades e interesses). Seguem algumas questões que poderão norteá-lo (a) na escrita. Conte-nos sobre

- sua história com a língua portuguesa. Por que você decidiu aprender português? Como foi seu primeiro contato com a língua? Como é a experiência de aprender uma língua no país onde ela é falada?

- suas experiências de aprendizagem de português na sala de aula. Que atividades, comportamentos e sentimentos facilitam ou dificultam sua aprendizagem em sala de aula?

- suas experiências de aprendizagem fora da sala de aula. De que forma você acredita que aprende português fora do contexto de ensino formal? Como você relaciona as experiências de aprendizagem fora da sala de aula com o que acontece em sala de aula e vice-versa?

- suas projeções em relação à aprendizagem do português. Quais são seus planos e intenções em relação à aprendizagem de língua portuguesa? De que forma saber o português impacta em sua vida? Muito obrigado por sua colaboração! (;) 